\title{
SCHSITOSOMA MANSONI CO-INFECTION WITH HEPATITIS C VIRUS IS ASSOCIATED WITH INCREASED INTERLEUKIN-28B PLASMA LEVELS IN EGYPTIAN POPULATION
}

\author{
By \\ SAMIRA Z. A. EID ${ }^{1}$, NOURTAN F. ABDELTAWAB ${ }^{2}$, SAMUEL T. MELEK ${ }^{1}$, \\ AND MAGDY A. AMIN ${ }^{2}$
}

Department of Parasitology and Blood Research ${ }^{1}$, National Organization for Drug Control and Research (NODCAR), Cairo12654, and Department of Microbiology and Immunology ${ }^{2}$, Faculty of Pharmacy, Cairo University, Cairo11562, Egypt

(*Correspondence nourtan.abdeltawab@pharma.cu.edu.eg)

\section{Abstract}

Intestinal schistosomiasis and hepatitis $\mathrm{C}$ viral (HCV) infections are endemic in Egypt with coinfections leading to increased severity of liver diseases. Previous studies characterized the immune responses to treatment in co-infection. However, little is known about the levels of interleukin 28B (IL-28B) in co-infection and its relation to endogenous gamma interferon (IFN- $\gamma$ ) levels. Therefore, a case-control study was performed comparing levels of IL-28B in relation to endogenous IFN- $\gamma$ in Schistosoma mansoni / HCV co-infected Egyptian patients compared to HCV mono-infected patients. Patients attending Kasr Al-Aini Hospital, Cairo from 2012-2014 were recruited. Subjects recruited were $S$. mansoni/HCV co-infected $(\mathrm{n}=22)$, treatment-naïve chronic HCV-4 $(n=50)$, and healthy controls $(n=35)$. Clinical history and liver function markers were determined for each participant. IL-28B and IFN- $\gamma$ plasma levels were assayed for all participants by ELISA and HCV load was quantified using Real-Time PCR. Plasma antischistosomal antibody titers were assayed along with viable egg identification in feces. Patients with high HCV viral load had significantly higher IFN- $\gamma$ and IL-28B levels whether suffering from HCV mono- or co-infection. Moreover, IFN- $\gamma$ levels were positively associated with IL28B plasma levels in HCV mono- and co-infection. The IL-28B levels were significantly higher in $S$. mansoni/HCV co-infected than $\mathrm{HCV}$ mono-infection patients $(\mathrm{p}<0.05)$.Data suggested that co-infection of HCV with S. mansoni affected IL-28B levels and IL-28B plasma levels might prove with sufficient further studies to be an effective prognosis biomarker for $S$. mansoni / HCV co-infection in the Egyptian population.

Keywords: Hepatitis C Virus, Schistosoma mansoni, co-infection, IFN- $\gamma$, IL-28B, biomarkers, tropical diseases

\section{Introduction}

Schistosomiasis is the second commonest parasitic disease in the world (Colley et al. 2014). An estimate of more than 200 million people worldwide are affected by schistosomal infection (Colley et al, 2014; Vos et al, 2012), with an estimated 83 million infected with $S$. mansoni (Crompton, 1999; Chitsulo et al, 2000). Schistosomiasis is a known endemic parasitic infection in Egypt since the Ancient times (Barakat, 2013; Othman and Soliman, 2015) affecting the liver as the main target organ and associated with liver fibrosis and cirrhosis in severe cases (Colley et al, 2014). Schistosomiasisin endemic regions contributes to comorbidity in co-infections with hepatitis, HIV, or malaria (Karp and Auwaerter,
2007; Abruzzi and Fried, 2011; Abruzzi et al, 2016).

Besides, the hepatitis $\mathrm{C}$ virus (HCV) infection represents a global burden with 130-200 million people infected worldwide (Seeff, 2002; Shepard, 2005). HCV is endemic in many countries, including Egypt, which has the highest worldwide incidence and prevalence of $\mathrm{HCV}$ genotype 4 up to $15 \%$ thus becoming a serious public health concern ( Kamal 2011; Guerra et al, 2012). Studies showed that differences in disease progression and outcomes are linked to host and viral factors. Host factors include the age, sex, genetic background, co-infection other disease as HIV and schistsomaisis, and affected the immune responses (Abdel-Hakeem and Shoukry, 2014). 
The burden of HCV and S. mansoni is of significant concern as the common coinfections of the parasite and virus lead to increased severity of the liver diseases. The prevalence of HCV in Egypt led to a bias for co-infection with $S$. mansoni (Strickland et al, 2002; Van-Lume et al, 2013; Loffredo-Verde et al, 2015; Abruzzi et al, 2016). Patients with co-infections showed higher HCV/RNA titers, more histological activity, greater cirrhosis, and higher mortality rates than those suffered from single infections (Pearce et al, 2002; Tanaka et al, 2004; Loffredo-Verde et al, 2015). The differential susceptibility to parasitosis was associated with genetic polymorphism of several cytokines (Fumagalli et al, 2009). IFN- $\gamma$, a Th1 cytokine associated with both diseases. Another important cytokine is IL28B belongs to type III interferon family of cytokines, and is also known as IFN- $\lambda$, part of the interferon-stimulated gene products (ISGs) (Schneider et al, 2014). ISGs are implicated in resistance of many pathogens including viral and parasites. Although IL$28 \mathrm{~B}$ gene polymorphism is linked to variation in response to $\mathrm{HCV}$ therapy $(\mathrm{Ge}$ et al, 2009), yet, in most of the IL-28B-HCV studies, the patient population with $S$. mansoni co-infection have been excluded.
Although studies have characterized immune response in $\mathrm{HCV}$ coinfection with $S$. mansoni, little is known about IL-28B levels in chronic $S$. mansoni/HCV patients and association with endogenous IFN- $\gamma$ levels.

The aim of the current study was to examine levels of endogenous IL-28B in treatment-naïve chronic $\mathrm{HCV}$ patients with or without $S$. mansoni co-infection as a biomarker for co-infection. The study found that IL-28B \& IFN- $\gamma$ levels correlate in $\mathrm{HCV}$ and $S$. mansoni/HCV co-infected patients. Moreover, IL-28B is higher in $S$. mansoni/HCV co-infected patients than mono-infected.

\section{Subjects and Methods}

Subjects: One twenty six subjects attending Kasr Al-Aini University's Hospitals, from 2012 to 2014 were recurited. They were from governorates of Cairo, Giza, Kafr El-Sheikh, Gharbia, and Menoufia, without history of pegylated-IFN treatment to assess endogenous IFN- $\gamma$ levels. Exclusion criteria included serious co-morbid conditions as heart diseases, poorly controlled diabetes to exclude insulin resistance as a negative predictive factor at baseline hepatic disorders, \& other concomitant viral or parasitic infections (Tab. 1).

Table 1: Inclusion and exclusion criteria for recruited $\mathrm{HCV}$ and S. mansoni/HCV patients.

\begin{tabular}{|l|l|}
\hline Inclusion criteria & Exclusion criteria \\
\hline Age $\geq 30$ yrs and $\leq 85$ yrs. & Serious co-morbid conditions such as severe arterial hypertension, heart failure, sig- \\
Positive HCV antibodies and & nificant coronary heart disease, poorly controlled diabetes (Hb,A1C $>8.5 \%$ ), chronic \\
detectable HCV RNA by PCR. & obstructive pulmonary disease. \\
Negative treatment history with & Major uncontrolled depressive illness. \\
PEG-IFN and RIB. & Solid transplant organ (renal, heart, or lung). \\
Hepatitis B surface antigen & Untreated thyroid disease. \\
negativity. & History of previous anti-HCV therapy. \\
Complete blood count taken & Known HIV co-infection. \\
into consideration. & Concomitant liver disease other than hepatitis C (chronic hepatitis B, autoimmune \\
& hepatitis, alcoholic liver disease, hemochromatosis, $\alpha-1$ antitrypsin deficiency, Wil- \\
& son's disease). \\
& Concomitant parasitosis or infection with Schistosoma species other than S. mansoni. \\
\hline
\end{tabular}

PEG-IFN: Pegylated-interferon; RIB: Ribavirin; HIV: Human immunodeficiency virus.

Sample size was calculated based on previously concluded statistical equation (Charan, 2013). Target population size was assumed unlimited, confidence interval (CI\%) was set to be within $\pm 10 \%$, confidence level was set at $95 \%$, and value of
0.5 was selected for standard deviation. The final number of participants who met inclusion criteria was 107 subjects. These were chronic S. mansoni / HCV co-infected patients $(\mathrm{n}=22)$, chronic HCV genotype-4 treatment-naïve patients $(n=50)$, and the 
healthy controls $(n=35)$. It was difficult to recruit $S$. mansoni mono-infected patients, as this group of patients is currently scarce in Egypt. This is partly due to the high $\mathrm{HCV}$ prevalence in Egypt that surpassed the $S$. mansoni mono-infected population led to bias towards co-infection ( Strickland et al, 2002; Kamal et al, 2004; Farid et al, 2005; Van-Lume et al, 2013; LoffredoVerde et al, 2015; Abruzzi et al, 2016). The choice of control subjects was tied to meet the study inclusion and exclusion criteria and difference in age range was kept minimal.

The study protocol conformed to the ethical guidelines of the 1975 Declaration of Helsinki. Patient's verbal approval was obtained from each patient before blood drawing. Additionally, the Research Ethics Committee (REC) of Faculty of Pharmacy, Cairo University, Egypt, approved this study, protocol number MI (522).

Liver function tests: Plasma levels of aspartate transaminase (AST), alkaline phosphatase (ALP), alanine transaminase (ALT), total and direct bilirubin were assayed using colorimetric kits from Quimica Clinica Aplicada, S.A. (QCA) (Tarragona, Spain). Gamma glutamyl transferase $(\gamma-$ GT) plasma levels were assayed using colorimetric assay (Reactivos GPL, Spain). Total plasma protein was assayed using biuret reaction method while albumin was assayed using bromocresol green reaction (BCG) both kits from (Stanbio Laboratory, Texas, USA).

Viral assays: Qualitative hepatitis B surface antigen (HBsAg) test was performed with ABON HBsAg Rapid Test (Abon Biopharm Co., Ltd., China). Quantitative hepatitis $\mathrm{C}$ viral load was quantified using real-time PCR method. To quantify HCV viral load, total viral RNA was isolated from patients' plasma using QIAamp viral RNA kit (Qiagen, Germany) following manufacturer's protocol. Real-time PCR for measuring $\mathrm{HCV}$ viral load using Quanti-Tect Probe RT-PCR Kit (Qiagen, Germany) was performed as previously described (Gibellini et al. 2006). This method assesses a standard by scalar dilution of control plasma used for the HCV b-DNA technique. HCV stock virus concentration contained $2.5 \times 10^{6}$ RNA copies $/ \mathrm{ml}(\mathrm{cpm})$. Prior to RNA purification procedure, the $\mathrm{HCV}$ stock was diluted in $\mathrm{HCV}$ - negative plasma to achieve several HCV scalar dilutions (from $5 \times 10^{5}$ copies to $50 \mathrm{cpm}$ ). Results $>10 \mathrm{cpm}$ were considered positive.

$S$. mansoni assays: Plasma antischistosomal antibody titers were assayed for all subjects using Bilharzial IHA kit (Fumouze Diagnostics, France). Titers $>$ 1:160 were considered significant, and any titers below this cutoff was considered indeterminate following established protocols (Van Gool et al, 2002; Kinkel et al, 2012). For confirmation of active $S$. mansoni infection, viable $S$. mansoni eggs were detected in schistosomiasis patients' feces using rectal snips.

Cytokine assay: IFN- $\gamma$ plasma levels were assayed using solid phase enzyme amplified sensitivity immunoassay DIAsource IFN- $\gamma$-EASIA (DIAsource Immunoassays, Belgium). IL-28B levels in plasma were measured using ELISA kit for human IFN-lambda-3 (EIAab Co., Ltd., China).

Statistical analysis: Data plotting was done using GraphPad Prism v6.01 (GraphPad Software Inc., California, USA). Nonparametric Mann-Whitney t-test was performed to calculate the differences between each pair of groups and data were expressed as medians \pm interquartile range (IQR). Spearman's correlation coefficient was calculated for each pair of data within each group. $\mathrm{P}<0.05$ and $95 \%$ confidence interval were used as significance cut-off limits for all significance tests.

\section{Results}

The results are in tables $(1 \& 2)$ and figures $(1,2,3 \& 4)$ 
Table 2: Demographics, HCV viral load, S. mansoni titer, and plasma levels of liver enzymes in chronic HCV and HCV / S. mansoni co-infected patients in comparison to healthy controls:

${ }^{a}$ significant difference between chronic HCV patients and healthy control groups $(p<0.0001),{ }^{b}$ significant difference between $S$. mansoni / HCV co-infected patients and healthy controls groups $(p<0.0001),{ }^{c}$ significant difference between chronic HCV \& S. mansoni / HCV co-infected patients $(p<0.05),{ }^{d}$ data expressed as medians \pm interquartile range (IQR)

\begin{tabular}{|l|l|l|l|}
\hline Parameters & Controls $(\mathrm{n}=35)$ & Chronic HCV patients $(\mathrm{n}=50)$ & S. mansoni $/ \mathrm{HCV}$ patients $(\mathrm{n}=22)$ \\
\hline Median age $\pm \mathrm{IQR}($ range) & $(32-47) 41.0 \pm 6$ & $(30-81) 44.5 \pm 12$ & $(31-51) 43.5 \pm 13.5$ \\
\hline Male: female & $18: 17$ & $23: 27$ & $16: 6$ \\
\hline Geographical distribution & & & \\
\hline Cairo (\%) & $27(77 \%)$ & $31(62 \%)$ & $3(14 \%)$ \\
\hline Delta (\%) & $8(23 \%)$ & $19(38 \%)$ & $19(86 \%)$ \\
\hline $\begin{array}{l}\text { Anti-S. mansoni titer } \pm \mathrm{IQR} \\
\text { (range) }\end{array}$ & $\begin{array}{l}80.0 \pm 0.0 \\
(80-160)\end{array}$ & $\begin{array}{l}160.0 \pm 80 \\
(80-160)\end{array}$ & $\begin{array}{l}320.0 \pm 0.0^{b, c} \\
(320-1280)\end{array}$ \\
\hline Liver profile & & & \\
\hline AST (IU/L) $\pm \mathrm{IQR}$ & $27.0 \pm 5.0$ & $270 \pm 30^{a}$ & $312.5 \pm 60.5^{b, c}$ \\
\hline ALT (IU/L) $\pm \mathrm{IQR}$ & $17.0 \pm 3.5$ & $240.5 \pm 41.3^{a}$ & $292.0 \pm 58.5^{b, c}$ \\
\hline AST/ALT ratio & $1.7 \pm 0.24$ & $1.1 \pm 0.09^{a}$ & $1.1 \pm 0.06^{b, c}$ \\
\hline$\gamma \mathrm{GT}(\mathrm{IU} / \mathrm{L}) \pm \mathrm{IQR}$ & $15.0 \pm 4.0$ & $123.8 \pm 15.9^{a}$ & $230.6 \pm 24 .^{b, c}$ \\
\hline ALP (IU/L) $\pm \mathrm{IQR}$ & $87.0 \pm 22.0$ & $282.6 \pm 64.3$ & $327.2 \pm 79.8^{b}$ \\
\hline Total protein (g/dl) $\pm \mathrm{IQR}$ & $6.8 \pm 0.4$ & $4.8 \pm 0.9^{a}$ & $3.4 \pm 1.8^{b, c}$ \\
\hline Albumin (g/dl) $\pm \mathrm{IQR}$ & $4.9 \pm 0.5$ & $3.0 \pm 0.4^{a}$ & $2.1 \pm 0.6^{b, c}$ \\
\hline Total bilirubin (mg/dl) $\pm \mathrm{IQR}$ & $0.2 \pm 0.035$ & $4.6 \pm 3.9^{a}$ & $3.8 \pm 4.2^{b}$ \\
\hline Direct Bilirubin $(\mathrm{mg} / \mathrm{dl}) \pm \mathrm{IQR}$ & $0.1 \pm 0.025$ & $2.3 \pm 1.9^{a}$ & $2.0 \pm 1.3^{b}$ \\
\hline
\end{tabular}

\section{Discussion}

Schistosomiasis when complicated with HCV aggravates liver disease complications and the worsens disease prognosis (Kamal et al, 2006). IL-28B \& IFN- $\gamma$ are two cytokines recognized in both diseases. The present study investigated the behavior and relationship between IL-28B and endogenous IFN- $\gamma$ in patients with $S$. mansoni complicated with HCV coinfection. To do so, general liver profile, viral load, S. mansoni antibody titers, microscopical stool analysis, and IFN- $\gamma$ and IL-28B cytokines levels in chronic treatment-naïve HCV patients with or without $S$. mansoni coinfection were compared to healthy donors as controls.

All subjects displayed negative $\mathrm{HBsAg}$, therefore, HBV can be excluded from causing liver damage and that liver disease could be mainly caused by either HCV in HCV patients or HCV complicated with $S$. mansoni in S. mansoi/HCV co-infected patients.

Liver enzymes levels of chronic HCV mono- and co-infection were elevated compared to healthy controls. Similar increase in the levels of these enzymes was previously reported by several studies (Halim et al, 1999; Van Gool et al, 2002; de Morais et al, 2010; Kinkel et al, 2012). This was basically that liver inflammation caused by HCV infection in HCV monoinfected patients. In $\mathrm{HCV}$ patients coinfected with $S$. mansoni, the same applies with an added liver damage caused by the parasite eggs located within the liver tissue. The presence of $S$. mansoni eggs induces the formation of granulomatous tissue, in turn, chemokines production leads to more cellular responses and aggravation of the inflammation and consequently leads to severe liver cellular damage (Smith et al, 2005).

Increased AST/ALT ratio was an important parameter for detecting progressive schistosomal or viral liver damage specifically liver cirrhosis and positive predictive value for detection of chronic liver disease. AST/ALT ratio was found to be $>1$ in both $\mathrm{HCV}$ mono-infected group and $\mathrm{HCV} / S$. mansoni coinfected group. This is an indication for severe liver disease caused by $\mathrm{HCV}$ infection either alone or accompanied by $S$. mansoni infection.

AST, ALT, \& $\gamma$-GT were higher in $S$. mansoni/HCV co-infection than $\mathrm{HCV}$ mono-infection $(p<0.0001)$. Similar data were reported (de Morais et al, 2010). However, some studies reported no signifi- 
cant difference in ALT or AST in the coinfected group compared to mono-infected group (Kamal et al, 2000). Others reported highly significant elevation in $\gamma$-GT in $\mathrm{HCV} / \mathrm{S}$. mansoni co-infection, being the highest in hepatosplenic schistosomiasis patients with decompensated liver cirrhosis. Saudy et al. (2012) showed similar results with lack of significant difference of ALP between HCV mono- and co-infection.

Total protein and albumin levels were significantly lower in both infected groups compared to controls $(p<0.0001)$ (Tab. 2). This is in agreement with previous reports (Fahim et al, 2000). S. mansoni/HCV coinfected patients showed significant decrease in total protein and albumin serum levels compared to mono-infected group ( $p$ $<0.01)$. Similar results regarding serum albumin were reported by de Morais (2010). The further decrease in total protein and persistently low albumin serum levels in liver disease signals reduced synthetic capacity of liver in co-infection, and it is a sign of progressive liver failure.

Total and direct bilirubin levels were significantly higher in both infected groups compared to control group ( $p<0.0001)$. These findings agreed with Halim (1999). On the other hand, there was no significant difference in total or direct bilirubin in the co-infected group compared to the HCV group. Others reported significantly higher total and direct bilirubin serum levels in coinfected group compared to HCV monoinfected group, which could be attributed to cholestasis or other accompanying liver damage that is not present in the current study (de Morais et al, 2010). Moreover, the present study results showed that conjugated (direct) bilirubin is elevated more than unconjugated (indirect) bilirubin, which typically indicates a problem associated with decreased elimination of bilirubin by the liver cells (Mcpherson, 2007).

HCV viral loads were expectedly significantly higher in HCV patients with or without $S$. mansoni co-infection compared to controls $(p<0.0001)$ (Fig. 1) with nonsignificant difference between HCV monoand co-infected patients. This disagreed where $\mathrm{HCV}$ patients co-infected with $S$. mansoni showed higher HCV viral loads and higher mortality rates compared with the patients infected with the HCV alone (Angelico et al, 1997: Kamal et al, 2000a, b). This contradiction could be attributed to that previous studies were based on longterm follow-up, whereas the current study was a case-control study. However, the current study finding is consistent with other studies of similar cross-sectional survey nature, without significant difference in HCV viral load between mono and coinfected HCV with $S$. mansoni (Farid et al, 2005; Allam et al, 2014).

IFN- $\gamma$ levels were positively associated with HCV viral load in mono-infection $(\mathrm{r}=$ $0.897, p<0.001)$ and co-infection $(\mathrm{r}=$ $0.949, p<0.001$ ) (Fig. 2a; b). This contradicts a previous study that showed that IFN- $\gamma$ did not correlate with $\mathrm{HCV}$ viral load in either groups (Emam et al. 2006). Such contradiction is probably attributed to the small sample size recruited for all groups, which could have affected the correlation analysis. Other studies showed inverse correlation between HCV viral load and HCV-specific CD4+ T-cells (Kamal et al. 2001). A possible explanation to this finding is the involvement of acute $\mathrm{HCV}$ patients, which expectedly has an enormous down-regulating impact on the initial cellular immune response due to the accelerated outburst of $\mathrm{HCV}$ replication. On the other hand, chronic infection tends to lower and stabilize the viral burden giving more chance to cellular immunity to improve commencing a positive correlation between IFN- $\gamma$ and HCV viral load. IL-28B levels were positively associated with $\mathrm{HCV}$ viral load in mono-infection $(\mathrm{r}=0.813, p<$ $0.001)$ and co-infection ( $\mathrm{r}=0.89, p<$ 0.001 ). The strong association of both cytokines with viral load was consistent that correlated IL-28B serum levels with the 
degree of $\mathrm{HCV}$ infection, regardless of concomitant S. mansoni infection (Al-Qahtani et al, 2015). Nevertheless, studies involving IL-28B as a serum cytokine in viral infection are relatively scarce.

One of the factors modulating the different outcomes of $S$. mansoni/HCV is Th1/ Th2 balance (Pearce, 2002). The present study showed a significant elevation of Th1 IFN- $\gamma$ in HCV subjects with or without $S$. mansoni co-infection compared to controls. However, IFN- $\gamma$ was non-significantly different between HCV mono- and co-infected groups. This can be attributed to the dominance of Th1 immune responses to $\mathrm{HCV}$ (El-Kady et al, 2005). Previous studies showed similar results, demonstrating no significant differences in the mean IFN- $\gamma$ among HCV patients coinfected with $S$. mansoni and those patients infected with HCV alone (Allam et al, 2014). Others have shown that IFN- $\gamma$ is higher in monothan co-infection (Badra et al, 2007). However, HCV-specific cell-mediated responses were not significantly different between the mono- or co-infected groups (Angelico et al, 1997; Saudy et al, 2012). S. mansoni causes liver pathology through an immunemediated mechanism rather than through direct hepatic injury (Hoffmann et al, 2000). S. mansoni ova were trapped in the liver, evoking a highly skewed Th2 immune response profile with the granuloma formation that progresses to periportal fibrosis. However, the ultrastructure and function of hepatocytes are minimally affected (El-Kady et al,2005). The Egyptian patients infected with HCV genotype-4 can mount $\mathrm{HCV}$-specific T-cell responses despite the prevalence of concomitant schistosomiasis (Angelico et al, 1997; Saudy et $a l, 2012$ ), but did not offer an explanation for the increased incidence in HCV morbidity observed in the co-infected patients (Badra et al, 2007).

Although IL-28B was associated with $\mathrm{HCV}$ infection, the current study further shows that in HCV co-infection with $S$. mansoni, IL-28 B levels further increase. Moreover, there are only two Egyptian studies that examined IL-28B, however, examining its genetic polymorphism not its plasma levels and in co-infected $\mathrm{HCV} / \mathrm{S}$. mansoni group rather than mono-infected S. mansoni group (Bakr et al, 2015; Shaala et al, 2015). A significant elevation of IL$28 \mathrm{~B}$ in $S$. mansoni/HCV co-infected patients was observed compared to $\mathrm{HCV}$ mono-infected group $(\mathrm{p}<0.05)$. The IL28B plays a specific role in inducing the production of IFN- $\gamma$ from CD8+ cells (Halim et al. 1999). This in turn shifts the immunological response to Th1 pathway which promotes cellular immunity and healing (Morrow et al, 2009).

In $\mathrm{HCV}$, resolution is usually associated with a complex Th1 response (AbdelHakeem et al, 2014) and S. mansoni associated with a mixed Th1 and Th2 responses with a shift to Th2. Moreover, several populations of HCV-specific CD4+ T-helper cells are primed including Th1 cells that provide help for CD8-mediated killing of infected hepatocytes by producing IFN- $\gamma$ and TNF $\alpha$, Th17 cells, and Th2 cells that provide help for antibody-producing B cells and generating antibodies via IL-4 and IL-6 (Abdel-Hakeem et al, 2014). The present study showed that a significant increase in IL-28B is case of parasitic S. mansoni coinfection that follows Th1 immunological pathway (Farid et al, 2005). Therefore, the current study data suggests that this elevation might be some sort of a compensation mechanism in chronic stages of parasitic co-infection to re-shift the persistent destructive Th2 pathway back to Th1 healing stage. Moreover, IL-28B gene polymorphism has been shown useful in predicting outcomes of HCV mono-infection treatment (Bochud et al. 2011). However, a recent study on predictive factors for $S$. mansoni/HCV patients showed that viral load and rapid virologic responses (RVR) were more valuable than IL-28B gene polymorphism in $\mathrm{HCV}$-genotype 4 prevalent in 
Egypt (Shaala et al, 2014). However, this study did not investigate whether IL-28B plasma levels rather than gene polymorphism could be the possible cost-effective biomarker for predicting therapy outcomes in $S$. mansoni/HCV patients. Further studies with more observations can clarify the relationship of IL-28B to balance of Th1, Th2 and Tregs responses in the naïve HCV patients with or without $S$. mansoni coinfection.

Correlation analysis showed that IFN- $\gamma$ levels were positively associated with IL28B levels in mono-infection $(\mathrm{r}=0.99, p<$ $0.0001)$ and co-infection $(\mathrm{r}=0.99, p<$ $0.0001)$. Similar findings were observed in influenza viral infection, where IL-28B and IFN- $\gamma$ were found to have a strong association (Morrow et al, 2010). These findings could be of clinical use, as IFN- $\gamma$ and IL$28 \mathrm{~B}$ are known to play major roles in the immune response to viral infection in general, and HCV as a special case. Both IFN$\gamma$ and IL-28B display not only antiviral activity, but also the antitumor and antiproliferative effects. This makes IL-28B a potential alternative to IFN- $\alpha$ for both antiviral and viral consequences as anticancer therapies. Unlike the IFN- $\alpha$ that is able to stimulate most cells, response to IL-28B stimulation is shown to be limited to dendritic, epithelial, and some tumor cells. Another difference was the ability of the IL28B stimulation to drive dendritic cells towards production of $\mathrm{CD} 4+\mathrm{CD} 25+\mathrm{FoxP} 3+$ regulatory $\mathrm{T}$-cells, suggested the possible immunoregulatory role (Mennechet, 2006). The IL-28B was affected in HCV patients co-infected with $S$. mansoni, suggested association of S. mansoni with the increased IL-28B levels.

\section{Conclusion}

Undoubtedly, schistosomiasis and HCV are diseases of public health importance.

To the best of the authors' knowledge, this is the first report to show a strong association between IFN- $\gamma$ \& IL-28B in naïve chronic HCV patients with or without $S$. mansoni co-infection. IL-28B was only affected in HCV patients co-infected with $S$. mansoni, suggesting association of $S$. mansoni with increased IL-28B levels. Further studies should investigate the possibility of using IL-28B as a cost-effective biomarker for prognosis of $S$. mansoni/HCV co-infection. Studies must investigate the possibility of using IL-28B as a novel biomarker for therapy in $S$. mansoni/HCV coinfection.

\section{References}

Abdel-Hakeem, MS, Shoukry, NH, 2014: Protective immunity against hepatitis C: Many shades of gray. Frontiers Immunol. 5:1-19.

Abruzzi, Amy and Bernard Fried. 2011: Coinfection of Schistosoma (Trematoda) with bacteria, protozoa and helminths. Adv. Parasitol. 77:1-85.

Abruzzi, A, Bernard F, Sukaina, B, Alikhan. A, 2016: Coinfection of Schistosoma species with Hepatitis B or Hepatitis C Viruses. Elsevier Ltd.

Al-Qahtani, A, et al, 2015: Correlation between genetic variations and serum level of interleukin 28b with virus genotypes and disease progression in chronic hepatitis $\mathrm{C}$ virus infection. J. Immunol. Res. 15:1-10.

Allam, WR, et al, 2014: Schistosomiasis does not affect the outcome of HCV infection in genotype 4-infected patients. Am. J. Trop. Med. Hyg. 90, 5:823-9.

Angelico, M, et al, 1997: Chronic Liver Disease in the Alexandria Governorate, Egypt: Contribution of Schistosomiasis and Hepatitis Virus Infections. J. Hepatol. 26, 2:236-43.

Badra, GA, EL-Meghawry, A, El-Kenawy, SS, El-Refaie, AO, 2007: Hepatitis C virusspecific CD4+ \& CD 8+T cell responses in $\mathrm{HCV}$ and Schistosoma mansoni coinfection: Relation to progression of liver fibrosis. HAEMA 10, 1:53-60.

Bakr, A, et al, 2015: Interleukin 28B polymorphism as a predictor of response to Interferon therapy in Hepatitis C virus patients." Menoufia Medical Journal 28:670-76.

Barakat, M.R, 2013: Epidemiology of schistosomiasis in Egypt: Travel through time: Review. J. Adv. Res. 4, 5:425-32.

Bochud, PY, et al, 2011: IL28B Polymorphisms predict reduction of HCV RNA from the first day of therapy in chronic hepatitis C. J. 
Hepatol. 55, 5:980-8.

Charan, J, Tamoghna, B, 2013: How to calculate sample size for different study designs in medical research? Indian J. Psychological. Med. 35, 2:121-6.

Chitsulo, L, Engels, D, Montresor, A, Savioli, L, 2000: The global status of schistosomiasis and its control. Acta Trop. 77, 1:41-51.

Colley, Daniel G., Amaya L. Bustinduy, W. Evan Secor, Charles H. King. 2014: Human Schistosomiasis. Lancet 383, 9936:2253-64.

Crompton, DW, 1999: How much human helminthiasis is there in the world? J. Parasitol. 85, 3:397-403.

Dongliang, G, et al, 2009: Genetic variation in IL28B predicts hepatitis C treatment-induced viral clearance. Nature 461, 7262:399-401.

El-Kady, I.M, Lotfy, M, Badra, G, El-Masry, S, Waked, I, 2005: Interleukin (IL)-4, IL10, IL-18 and IFN-gamma cytokines pattern in patients with combined hepatitis $\mathrm{C}$ virus and Schistosoma mansoni infections. Scandin. J. Immunol. 61, 1:87-91.

Emam, A., Emam, M,. Shehata, AE, Mahmoud, E, 2006: Impact of Schistosoma mansoni co-infection on serum profile of the interferon-gamma, interleukin-4 and interleukin-10 in patients with chronic hepatitis $\mathrm{C}$ virus infection. Egypt. J. Immunol. 13, 2:33-40.

Fahim, FA, Esmat, AY, Hassan, GK, AbdelBary, A, 2000: Biochemical changes in patients with combined chronic schistosomiasis and viral hepatitis C infections. Dis. Mark. 16, 3/4:111-8.

Farid, A, et al, 2005: Schistosoma infection inhibits cellular immune responses to core HCV peptides. Parasite Immunol. 27, 5:189-96.

Fumagalli, M, et al, 2009: Parasites represent a major selective force for interleukin genes and shape the genetic predisposition to the autoimmune conditions. J. Exp. Med. 206, 6: 1395-408.

Gibellini, D, et al, 2006: Simultaneous detection of HCV and HIV-1 by SYBR Green real time multiplex RT-PCR technique in plasma samples. Mol. Cell. Probes 20, 3/4:22-9.

Van Gool, T,et al, 2002: Serodiagnosis of the imported schistosomiasis by a combination of a commercial indirect hemagglutination test with Schistosoma mansoni adult worm: Antigens and an enzyme-linked immunosorbent assay with S. mansoni egg antigens. J. Clin. Microbiol. 40, 9:3432-7.
Guerra, J, Garenne, M, Mohamed, MK, Fontanet, A, 2012: HCV burden of infection in Egypt: Results from a nationwide survey. J.Vir. Hepat. 19, 8:560-7.

Halim, Abdel-baset, Robert F. Garry, Srikanta Dash, and Michael A. Gerber. 1999: Effect of schistosomiasis and hepatitis on Liver. Am. J.Trop. Med. Hyg. 60, 6:915-20.

Hoffmann, KF, Cheever, AW, Wynn, TA, 2000: IL-10 and the dangers of immune polarization: Excessive type 1 and type 2 cytokine responses induce distinct forms of the lethal immunopathology in the murine schistosomiasis. J. Immunol. 164, 12:6406-16.

Kamal, SM, et al, 2000: Clinical, Virological and Histopathological Features: Long-Term Follow-up in Patients with Chronic Hepatitis C Co-Infected with S. mansoni. Denmark.

Kamal, SM, et al, 2001: Acute hepatitis C without and with schistosomiasis: Correlation with hepatitis C-specific CD4+ T-Cell and cytokine response. Gastroenterol. 121, 3:64656.

Kamal, SM, et al, 2004: Kinetics of intrahepatic hepatitis $\mathrm{C}$ virus (HCV)-specific CD4+ $\mathrm{T}$ cell responses in $\mathrm{HCV}$ and Schistosoma nansoni coinfection: Relation to progression of liver fibrosis. J. Infect. Dis. 189, 7:1140-50.

Kamal, SM, et al, 2006: Progression of fibrosis in hepatitis $\mathrm{C}$ with and without schistosomiasis: Correlation with serum markers of fibrosis. Hepatol. 43, 4:771-9.

Kamal, SM, et al, 20011: Hepatitis C virus genotype 4 therapy: progress and challenges. Liver Int. J. 31, 1:S45-52.

Kamal SM, Madwar MA, Peters T, Fawzy R, Rasenack J. et al, 2000: Interferon therapy in patients with chronic hepatitis $\mathrm{C}$ and schistosomiasis. J. Hepatol. 32, 1:172-4.

Karp, Christopher L, Paul G. Auwaerter. 2007: Coinfection with HIV and tropical infectious diseases. II. Helminthic, fungal, bacterial, and viral pathogens: Official publication of the Infectious Diseases Society of America. Clin. Infect Dis. 45, 9:1214-20.

Kinkel, HF, Dittrich, S, Britta Baümer, B, Weitzel, T, 2012: Evaluation of eight serological tests for diagnosis of imported schistosomiasis. Clin. Vac. Immunol. 19, 6:948-53.

Loffredo-Verde, E, et al, 2015: Schistosome infection aggravates HCV-related liver disease and Induces Changes in the Regulatory T-Cell Phenotype. Parasite Immunol. 37, 2:97-104. 
Mcpherson, R, Richard A, Matthew, R, Pincus, A, 2007: Henry's Clinical Diagnosis and Management by Laboratory Methods. Philadelphia. Saunders.

Mennechet, FJD, Gilles UZÉ, 2006: Interferon- $\lambda$-treated dendritic cells specifically Induce proliferation of FOXP3-expressing suppressor $t$ cells. Blood 107, 11:4417-23.

de Morais, C, Neuenschwander, L, et al, 2010: Correlation of biological serum markers with the degree of hepatic fibrosis and the necroinflammatory activity in hepatitis $\mathrm{C}$ and schistosomiasis patients. Mem. Inst. Oswaldo Cruz, Rio De Janeiro 105, 4:460-6.

Morrow, MP, et al, 2009: Comparative ability of IL-12 and IL-28B to regulate treg populations and enhance adaptive cellular immunity. Blood 113, 23:5868-77.

Morrow, MP, et al, 2010: Unique Th1/Th2 phenotypes induced during priming and the memory phases by use of interleukin-12 (IL12) or IL-28B vaccine adjuvants in Rhesus macaques. Clin. Vac. Immunol. 17, 10:1493-9. Othman, AA, Soliman, RH, 2015: Schistosomiasis in Egypt: A never-ending story? Acta Trop. 48:179-90.

Saudy, N, Elghannam, DM, Farag, R, Abd El-Maksoud, M, El-Hussiny, MA, et al, 2012: Study of some fibrosis indices in genotype $4 \mathrm{HCV}$ infected Egyptian patients. Life Sci.J. 9, 1:972-84.

Pearce, EJ, MacDonald, AS, 2002: Immunobiology of schistosomiasis. Nat. Rev. Immunol. 2, 7:499-511.
Schneider, A, William, M, Chevillotte, DM, Charles, MR, 2014: The interferon-stimulated genes: A complex web of host defenses. Ann. Rev. Immunol.32:513-45.

Seeff, Leonard B. 2002: Natural history of chronic hepatitis C. Hepatol. 36, 5:S35-46.

Shaala, AY, et al, 2014: The role of IL-28B polymorphisms in virologic response to combined pegylated interferon and ribavirin therapy in genotype 4 chronic HCV infected patients with and without cirrhosis. Alex. J. Med. 51, 3:231-9.

Shepard, CW, Finelli, L, Alter. MJ, 2005: Global epidemiology of hepatitis $\mathrm{C}$ virus infection. Lancet Infect. Dis. 5, 9:558-67.

Smith, P, et al, 2005: Schistosoma mansoni secretes a chemokine binding protein with antiinflammatory activity. J. Exp. Med. 202, 10:1319-25.

Strickland, GT, et al, 2002: Role of hepatitis $\mathrm{C}$ infection in chronic liver disease in Egypt. The Am. J. Trop. Med. Hyg. 67, 4:436-42.

Tanaka, Y, et al, 2004: Exponential spread of hepatitis C Virus Genotype 4a in Egypt." J. Mol. Evol. 58, 2:191-5.

Van-Lume, DS, et al, 2013: The association between schistosomiasis mansoni and hepatitis C: Systematic review. Rev. Saude Publ. 47, 2:414-24.

Vos, T, et al, 2012: Years lived with disability for 1160 sequelae of 289 diseases and injuries 1990-2010: A systematic analysis for the global burden of disease study 2010. Lancet 380, 9859:2163-96.

\section{Figure Legends}

Fig, 1: HCV viral load in healthy controls vs. chronic HCV and S. mansoni / HCV co-infected patients. HCV viral RNA load (cpm) was measured by assaying viral RNA using quantitative Real-Time PCR. Both HCV mono- and co-infected groups had significantly high levels of viral RNA $(p<0.0001)$ values are plotted as medians and Mann-Whitney test used for statistical comparison of each two groups.

Fig. 2: Correlation analysis of HCV viral RNA load (x104 cpm) with endogenous IFN- $\gamma$ levels (IU/ml) and IL-28B levels $(\mathrm{pg} / \mathrm{ml})$. Correlation analysis showed positive association between endogenous IFN- $\gamma$ levels \& HCV viral load. Patients with high HCV viral load had significantly higher IFN- $\gamma$ levels whether suffering from (a) mono-infection $(\mathrm{r}=0.8975, p<$ $0.001)$ or (b) co-infection $(r=0.9493, p<0.001)$. Similarly, IL-28B levels significantly higher in patients with high HCV load whether suffering from (c) mono-infection $(\mathrm{r}=0.8133, p<0.001)$ or $(\mathrm{d})$ co-infection $(\mathrm{r}=0.8905, p<0.001)$, where $\mathrm{r}$ Spearman's correlation coefficient.

Fig. 3: Endogenous IFN- $\gamma$ levels $(\mathrm{IU} / \mathrm{ml})$ and IL-28B levels $(\mathrm{pg} / \mathrm{ml})$ in healthy controls vs. chronic HCV and S. mansoni $/ \mathrm{HCV}$ co-infected patients. (a) IFN- $\gamma$ levels showed no significant difference between HCV mono- and co-infected groups. Meanwhile, IL-28B levels (b) were significantly higher in S. mansoni/ HCV group $(p<0.05)$. All values plotted as medians and Mann-Whitney test used for statistical comparison of each two groups.

Fig. 4: Correlation analysis between levels of IL-28B levels (pg/ml) and endogenous IFN- $\gamma$ levels (IU/ml) showed positive association in chronic HCV mono-infected patients (red dots and regression line) $(\mathrm{r}=0.99, p<0.0001)$ and $S$. mansoni /HCV co-infected patients (purple dots and regression line) $(\mathrm{r}=0.99, p<0.0001)$, but not in healthy controls (green dots and regression line) $(\mathrm{r}=0.20, p>0.05)$, where $\mathrm{r}$ is Spearman's correlation coefficient. 


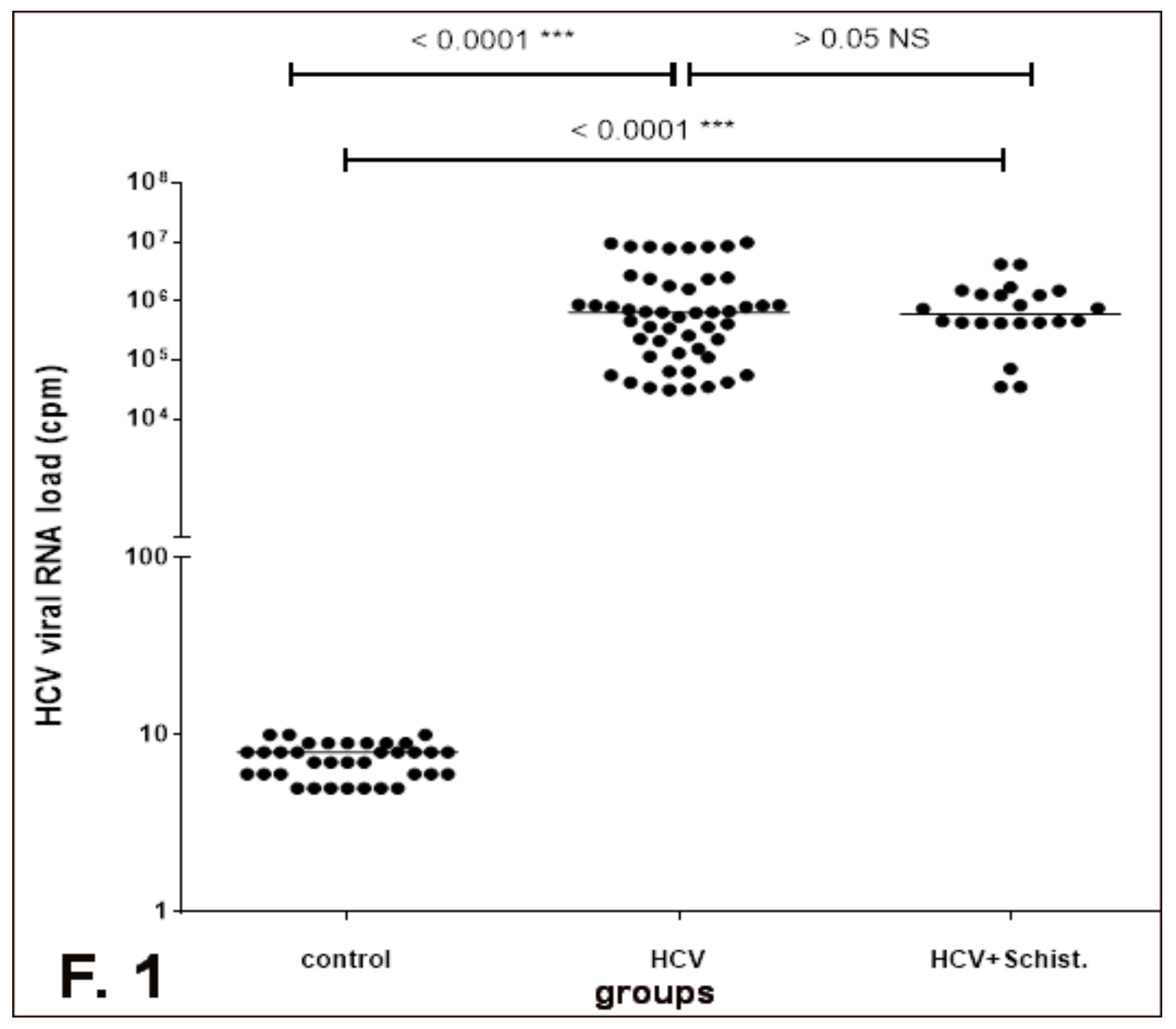




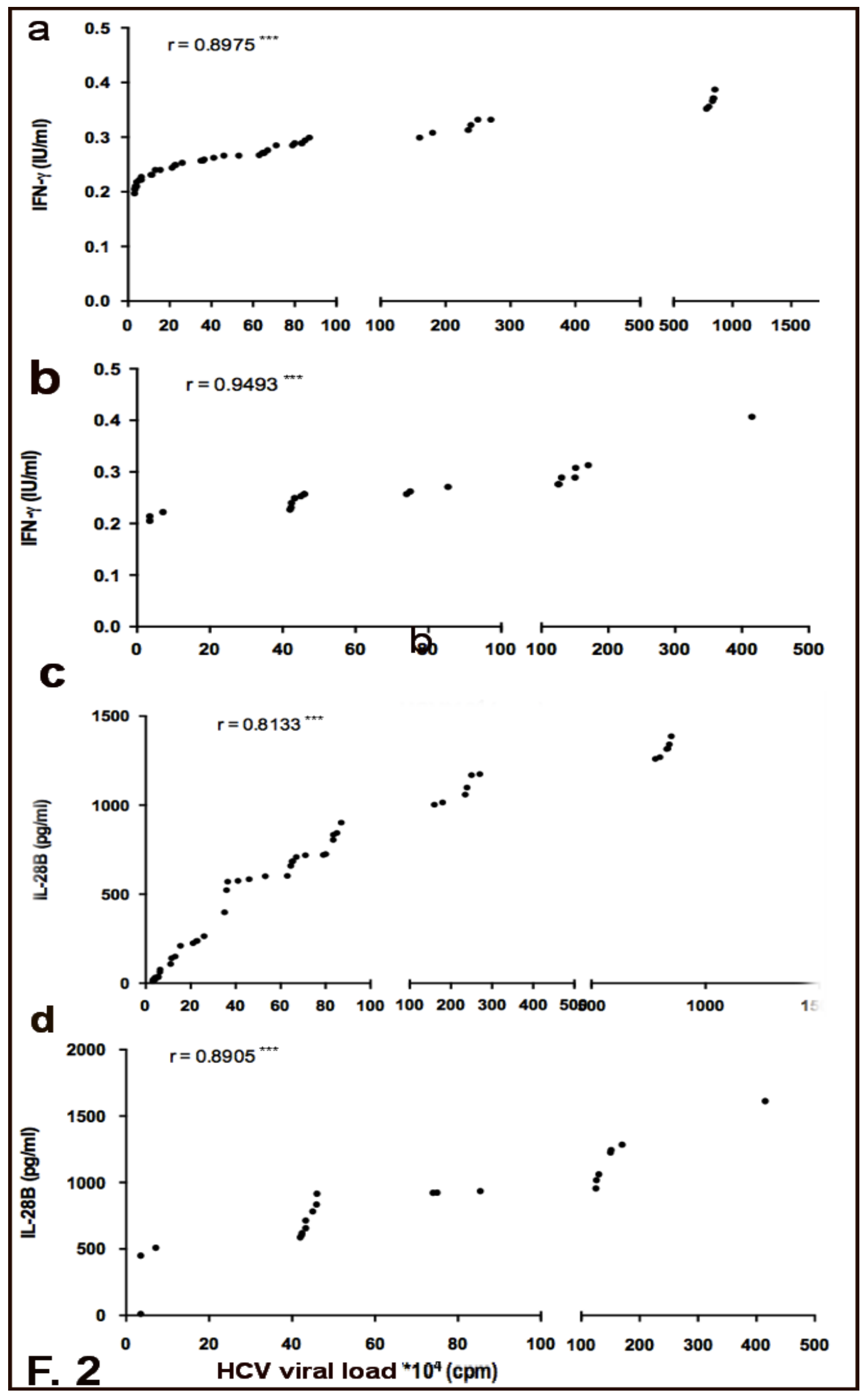



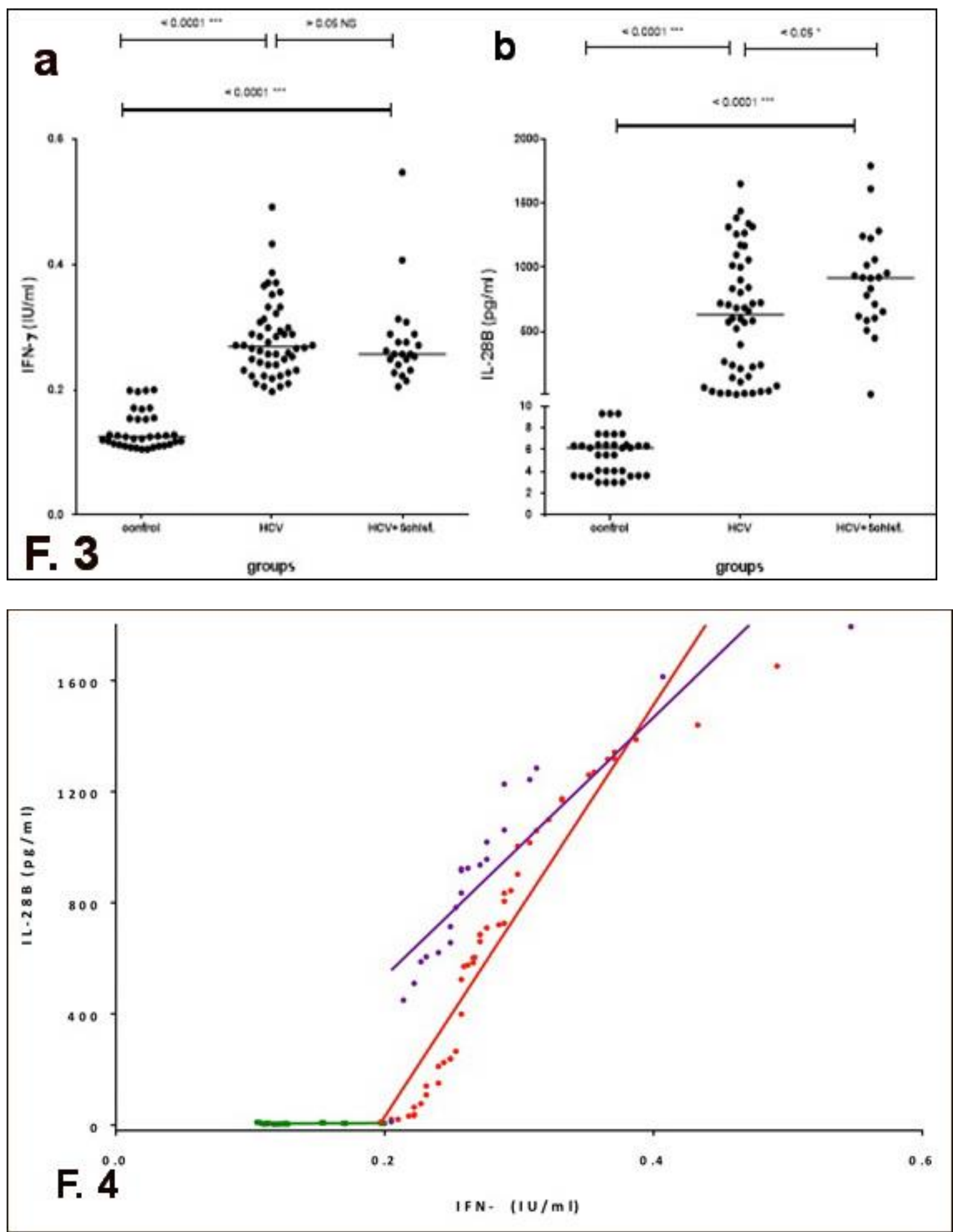